\title{
Lectoras del siglo XIX. Imaginarios y prácticas en la Argentina
}

Batticuore, Graciela (2017). Buenos Aires: Ampersand, 176 pp.

\section{Ana Eugenia Vázquez UBA-CONICET}

La lectora es, sin dudas, una figura de origen decimonónico. Tal como lo ha demostrado la historia del libro y la lectura, es en el siglo XIX cuando las mujeres tienen acceso al escrito por primera vez, lo que fue posible gracias a la democratización del impreso, facilitada por la prensa, y el incremento de la alfabetización. Con este fenómeno, aparecen las primeras publicaciones dirigidas al público femenino, donde se ofrecían figurines de moda, recetas de cocina, consejos para las amas de casa y, especialmente, folletines. En el siglo XIX también, la novela se transforma en el género dominante de la literatura europea y americana, cuyos efectos nocivos sobre el público femenino conformaron un leitmotiv en los dos mundos, ampliamente analizados por los Estudios de Género. El caso paradigmático es el de la Emma Bovary de Flaubert, pero muchos otros salpican el imaginario de la época: la Thérèse Raquin de Èmile Zola asesina a su marido inspirada en las novelas de crímenes que lee en los diarios, la americana Soledad, concebida por Bartolomé Mitre, se decide a engañar a su marido luego de leer Julia o la Nueva Heloisa. Los recelos se incrementan con la emergencia de las primeras escritoras que pretenden convertirse en autoras $y$, por lo tanto, en propietarias de sus ideas y destinos. Así, la imagen de la mujer con el libro en la mano sedujo y acechó a escritores, críticos y artistas a lo largo de todo el siglo. Por otro lado, es en el siglo XIX cuando la escritura se vuelve parte necesaria de la vida cotidiana y se expande lo que Roger Chartier denomina "écritures ordinaires": las cartas, los diarios íntimos, las esquelas, las notas, las listas se vuelven prácticas constitutivas de la subjetividad y la sociabilidad.

Sobre estos tres soportes tan decimonónicos como sus consumidores -la prensa, los epistolarios y la novela - se organiza el libro de Graciela Batticuore.
Lectoras del siglo XIX. Imaginarios y prácticas en la Argentina analiza las diversas representaciones de la mujer lectora en la cultura argentina desde principios del siglo XIX hasta comienzos del XX en tres capítulos: "La lectora de periódicos", "La lectora de cartas", "La lectora de novelas". La autora busca precisamente indagar aquello que se cifra en la escena enigmática y cautivadora de la mujer que lee: ¿cómo se la representó?, ¿por medio de qué lenguajes?, ¿bajo qué intenciones y preocupaciones?, pero también, ¿qué y cómo leyeron las mujeres de los siglos XIX y XX?, ¿cómo concibieron la relación entre lectura y vida?, ¿para qué leyeron?, ¿para consagrarse, educarse, enamorarse, establecer contacto con los seres queridos alejados por la guerra y la política?

En el primer capítulo, Batticuore rastrea una ausencia, que contrasta con la obsesión decimonónica por retratar a la lectora. Hasta principios del siglo XX serán pocas las representaciones de la lectora de prensa, escritura asociada a la vida pública y, por lo tanto, vedada a las mujeres. Por el contrario, señala, la concepción canónica de este tipo de lectura es la de una escena típicamente paternalista, en la que el hombre de la casa lee a las mujeres que se ocupan de las tareas domésticas seleccionando para ellas lo que considera adecuado. Así, sostiene Batticuore: "El hombre es el mediador de la lectura, el guía y el maestro de las mujeres de la casa (Batticuore, 2017: 24)". Sin embargo, ya desde principios de siglo, algunas voces se resistieron a la tutela masculina. Graciela Batticuore reconstruye cuidadosamente este derrotero. Desde 1802, entre las páginas de El Semanario de Agricultura, los redactores inician una reflexión sobre la educación femenina que atravesará la prensa del período revolucionario y se efectivizará en 1824 con la fundación de la Sociedad de Beneficencia a cargo de 
Rivadavia. Real o impostada, estos periódicos construyen por primera vez en el Río de la Plata la figura de la corresponsal, es decir, la de la lectora que se atreve a escribir. También presentan la organización de una sociedad de lectura femenina, "Las Amigas de El Observador". De entre ellas, emerge Emilia P., una provocadora dama porteña que se queja con ironía de las preferencias masculinas, críticas de la escaza instrucción de las mujeres, pero elogiosas de su belleza. Emilia concluye: "Revolución sería cambiar lo que los hombres quieren de las mujeres" $(2017,39)$. Ahora bien, por fuera de estas figuraciones textuales, se pregunta la autora ¿qué hay de real?, ¿qué se sabe sobre las prácticas lectoras efectivas de las argentinas de la época? Para responder tales interrogantes, Batticuore analiza el caso de Mariquita Sánchez de Thompson, miembro distinguido de la elite porteña, que durante la época del exilio fue una activa colaboradora de los románticos, manteniéndolos informados de los principales sucesos porteños. Otra notable lectora de periódicos fue Encarnación Ezcurra, quien también desempeñó el papel de informadora para su marido, Juan Manuel de Rosas.

En 1830 se producirá otra novedad elocuente con la aparición de La Aljaba, primer periódico literario dirigido al público femenino y redactado por una mujer, Petrona Rosende de Sierra. Ese mismo año, Luis Pérez publica El Gaucho, seguido poco tiempo después por La Gaucha, donde se figura por primera vez a otra lectora, la gaucha gacetera. Ambos semanarios, a pesar de sus diferencias, enarbolan una prédica común respecto del rol social de las mujeres: criatura pacificadora, “ángel del hogar”, ella debe permanecer en la vivienda, alejada de la política, para así paliar los males que la lucha facciosa había provocado en la sociedad. En consonancia con estas ideas, los escritores de la época también se alimentaron del imaginario de la mujer lectora de periódicos. A partir de la doña Marcelina de Amalia y la Medea de La gran aldea, Batticuore explora la representación monstruosa y masculinizada de los personajes femeninos que leen la prensa. A partir de 1880 , se perfilan otras figuras: la lectora burguesa de la página bursátil y la militante anarquista, también representadas bajo el registro de lo monstruoso encarnan los males importados por la modernidad al Río de la Plata y la amenaza constante de la mujer que quiere intervenir en la política.

En “La lectora de cartas", la autora analiza otro peligro que conjura la lectura femenina, el de una lectora erotizada. Las misivas de Guadalupe Cuenca a su marido Mariano Moreno o las de Tomás Guido y Vicente Fidel López a sus novias, inscriptas en la lógica de la pasión, la demora y la reciprocidad, revelan los fatídicos cruces entre política y amor en la Argentina decimonónica. A continuación, Batticuore se detiene en el retrato de una de las mujeres más enigmáticas y polémicas de la historia nacional, aquel de Manuelita Rosas que por 1851 realizó Prilidiano Pueyrredón y donde la hija del restaurador aparece apoyando su mano sobre una esquela. El pintor ejecutó un estudio previo a la realización de la pintura, cuyas variaciones, en particular la sustitución de un libro por una carta, Batticuore interpreta con agudeza: en lugar de representarla como una lectora romántica, la epístola asocia a Manuelita a la tradicional figura del "ángel del hogar", "mediadora amorosa, compasiva y misericordiosa entre él [Rosas] y su pueblo" (2017: 102). Otras modulaciones de esta figura aparecen a medida que la práctica de la escritura epistolar se extiende: la analfabeta que desconoce los códigos de urbanidad, las letradas que hacen de ellos un arte, la madre que enseña a leer a sus hijos en el archivo epistolar familiar. Con el paso de los años, el imaginario de la lectora de cartas se asocia cada vez más a la intimidad. Aunque se aleja de los avatares de la vida política, reproduce una nueva preocupación moral, vinculada a las consecuencias nocivas de la modernización sobre los valores tradicionales, descomposición social que exhiben descarnadamente las novelas de Cambaceres.

En el tercer capítulo, Batticuore aborda la figura de la lectora de novelas, género que constituyó el epítome de la mala lectura, pero cuyo éxito irrefutable alimentó profusamente el imaginario artístico e intelectual desde principios de siglo XIX hasta entrado el XX. En este caso, la autora prefiere invertir el recorrido temporal e inicia esta sección con un análisis de aquellos films argentinos que reelaboraron clásicos literarios del XIX: de la Amalia de García Velloso a la Camila de María Luisa Bemberg, la lectura de ficción es una práctica asociada a lo prohibido y peligroso, especialmente en una sociedad atravesada por la guerra facciosa. El principal problema radica en que estos libros son fuente de una peligrosa educación sentimental, en el que las muchachas aprendían el amor y la pasión. Tal como sostiene la autora: "los libros de imaginación son lectura inflamable porque activan una sensibilidad femenina siempre propensa al desborde, a la fantasía, y que se resiste al control" (2017: 128). En efecto, el estatuto del género produjo posicionamientos diversos entre los románticos. Algunos, como Sarmiento, lo consideraban una vía privilegiada para impartir las luces de la civilización entre aquellos no habituados a las lecturas serias; otros sostenían su peligrosidad inapelable. De un modo u otro, la novela fue el consumo preferido de 
las lectoras americanas que no dudaron en retratarse con ellas, tal como hizo Lucía Carranza con su edición del Telémaco de Fénelon. Frente a tal furor, Batticuore indaga ingeniosamente las estrategias de una "censura solapada", desplegada con el fin de controlar los efectos perniciosos de la lectura de novelas: discursos críticos, traducciones atenuantes, arengas contra los folletinistas franceses y difusión de autores locales fueron algunas de los tantos procedimientos que se emplearon a nivel local, pero también en Europa, para calibrar la influencia de la lectura novelesca. Un caso emblemático al respecto lo constituye Juana Manuela Gorriti, que pudo transformarse en una de las primeras novelistas (y autoras) nacionales, gracias a una nutrida red de contactos que la promocionó haciendo hincapié en el aspecto moralizador de sus ficciones. "Entre la prohibición y el placer”, como reza uno de los subtítulos del capítulo, la novela siguió despertando profundos recelos, especialmente con la emergencia del naturalismo en el Río de la Plata hacia 1880 , así como también convocando el deseo y la pasión de lectores y lectoras voluptuosos, enamorados, apasionados. En este marco, la polémica se profundiza cuando son las mujeres las que intervienen y pretenden forjar una carrera literaria cultivando un género supuestamente corruptor e inmoral.

La hipótesis rectora del libro sostiene que la lectora resulta una figura siempre inquietante: promesa, por un lado, de la vida civilizada que las elites tanto ansiaron durante el arduo proceso de constitución nacional; por otro, enigma misterioso que sugiere la descomposición de los valores familiares y las incertidumbres de la modernidad. Para hallar las huellas fugaces de las prácticas lectoras femeninas, la autora se constituye a ella misma como la lectora atenta de un corpus tan fragmentario como heterogéneo: semanarios y gacetines, epistolarios, pinturas, fotografías, documentos fílmicos, novelas y poemas. Batticuore rescata y organiza papeles, pero también figuras: las damas federales son protagonistas de algunos de los análisis más sutiles y originales del libro en los que quedan al descubierto las continuidades con las que el imaginario masculino concibió a las mujeres, sean heroínas unitarias o enemigas federales.

Como escritora, Batticuore ofrece una prosa amena y sugerente, que no renuncia a la densidad interpretativa. Desde "Prismático" (prólogo), el libro se inscribe en dos registros simultáneos. Por un lado, Lectoras del siglo XIX es corolario de una extensa carrera académica dedicada a las complejas relaciones entre escritura, lectura y mujeres en el siglo XIX argentino. La erudición de las fuentes, la actualización bibliográfica, la habilidad en el armado de interpretaciones e hipótesis exhaustivas sobre un corpus disperso evidencian los años de trabajo en el archivo, la investigación y la docencia. Por otro lado, el libro ofrece la posibilidad de una lectura ensayística que abandona por momentos la exhaustividad explicativa en pos de la sugerencia y la asociación. Las imágenes son las protagonistas y disparadoras del libro, pero constituyen también un recurso de la escritura, un modo de bordear y pensar nuevamente las figuras de las mujeres que leen, que provienen del arte canónico, la literatura popular, el cine y la misma infancia de la autora y cuyos detalles - muchas veces inadvertidos- todavía signan nuestras prácticas lectoras. 
